\title{
Complementary or Integrative - Ideas and Notions
}

Every now and then the editors of Forschende KomplementärmedizIn / ReSEARCH IN ComplementaRy Medicine come together to discuss fundamental issues of publication strategy and trends in the field. At one of our last meetings we found that the age-old debate about what our scope actually is has been triggered once more by the newly emerging usage of the term 'Integrative Medicine'. We thought we should take up the discussion again to clarify these terminological issues. Meanwhile the CAMBRELLA project has been approved by the European Commission within its 7th Research Framework and part of it is a clarification of notions. That this is all but trivial can be seen in the contributions to this collection, where our editors share their own thoughts. We would welcome a broad discussion in the field and are happy to publish novel contributions and insights as letters or small essay pieces.

\section{Complementary? Alternative? Integrative?}

\author{
Harald Walach \\ Institute of Transcultural Health Sciences \\ European University Viadrina \\ Frankfurt/O, Germany
}

'Complementary', 'Alternative', or 'Integrative Medicine' are notions suggesting different relationships between conventional medicine and those treatment options outside the mainstream. I myself find 'Complementary Medicine' best. This is because complementarity implies wholeness that consists of opposites that are incompatible, yet are both needed to describe that whole $[1,2]$. This means that complementary medicine and conventional medicine are two ways to approach the problem of illness and healing that cannot be reduced to each other. This is more of a dialectical way of looking at the problem. The conventional approach is a useful way to solve problems, such as acute, life-threatening diseases or to fix injuries. It is less useful for solving complex problems and clarifying an intricate network of relationships, as in the treatment of chronic diseases [3]. There is a definite future for complementary medicine. There will always be some restless and inquisitive minds that are unhappy with the state of affairs, and that will be looking out for what has been missed, even at the cost of being shunned by the mainstream. But this is the dialectical engine of progress.

'Alternative Medicine' means that whatever is done is happening on the same line of reasoning and action, except it is the opposite of the orthodox model and can replace it. This is at least as dogmatic and totalitarian as the conventional way of thinking. 'Alternative Medicine' would love to be the orthodoxy itself, but, alas, cannot, because 'they' are too powerful and envious. This term is only helpful if we want to describe real alternatives, for instance if someone takes his mountain bike to ride across the Alps instead of undergoing the indicated chemotherapy for his cancer. Prof. Gerd Nagel once told me such a story of a patient. The guy rode his bike across the Alps and returned cured from his cancer.

'Integrative Medicine' is a bit subtler. This term suggests that one can combine elements of complementary with conventional medicine if they have been shown to be efficacious and evidence based. This sounds plausible. But the notion implies a colonialising stance. It implicitly supposes that the paradigmatic model and presuppositions of current practice are correct and not in need of revision. It supposes that progress is only dependent on effective methods of treatment. We know how to test such therapies, so we conduct those trials and whatever survives we take on board. It is as simple as that, isn't it? Too simple, I think [4]. 'Integrative Medicine' implicitly assumes our canon of methods is fixed, the paradigmatic foundations firm, and all we need is accumulation of knowledge onto those foundations using well-established methods. Integration implies a dangerous security about how to achieve such a progress. It reminds me of Lord Kelvin, who, at the end of the 19th century is said to have recommended a prospective student to not choose physics, as most problems had been solved and the rest were short of being solved. And then Quantum Mechanics arrived and physics became extremely interesting again. And exactly what was the basic paradigmatic insight beyond physics proper? Complementarity and the understanding that holism always implies two incompatible opposites that cannot be reduced to each other.

\section{KARGER}

Fax +497614520714

Information@Karger.de

www.karger.com (c) 2010 S. Karger GmbH, Freiburg

Accessible online at:

www.karger.com/fok 


\section{References}

1 Meyer-Abich KM: Korrespondenz, Individualität und Komplementarität. Wiesbaden, Steiner, 1965.

2 Walach H, Römer H: Complementarity is a useful concept for consciousness studies. A reminder. Neuroendocrinol Lett 2000;21:221-232.

3 Hyland ME: Extended network learning error: A new way of conceptualising chronic fatigue syndrome. Psychol Health 2001;16:273-287.

4 Walach H: The campaign against CAM and the notion of 'evidence-based'. J Altern Complement Med 2009;10:1139-1142.

\section{New Perspectives in Medicine Are Required - from CAM to Integrative Medicine}

\section{Benno Brinkhaus}

Institute of Social Medicine, Epidemiology, and Health Economics Charité - University Medical Center

Berlin, Germany

The terminology of 'Complementary and Alternative Medicine' (CAM), 'Complementary Medicine' (CM) and 'Integrative Medicine' (IM) has been an ongoing debate for several years $[1,2]$. The topic has already formed an object of debate at the 2nd European Congress for Integrative Medicine in Berlin, in 2009, organised by members of the International Society for Complementary Medicine Research (ISCMR).

I think the discussion of terminology issues in the field of CAM or CM is urgently needed, worthwhile, and can open new perspectives in this field of medicine. There are several reasons for questioning the term CAM with regard to its future:

Firstly, although the terms of CAM and CM are widely used in the scientific community, they have no commonly accepted definition. Many attempts to define CAM have been made, e.g. by the National Center for Complementary and Alternative Medicine (NCCAM), the World Health Organisation (WHO), or the Cochrane Collaboration. Notwithstanding the length of these definitions, they are mostly characterised by a lack of precision and a tendency to define the topic in negative terms.

Secondly, the terms CAM and CM are often used in an interchangeable fashion. Although they are attributed either to CAM (e.g. the NCCAM and the WHO definition) or to CM (e.g. the Cochrane definition), there is no clarification of how the two terms are to be differentiated.

Thirdly, although the term CAM has been used for more than 15 years, it is not used and accepted by the patients and physicians in conventional medicine. Most patients experience $\mathrm{CAM} / \mathrm{CM}$ as an abstract term but have no clear idea what it means.

Patients may request e.g., acupuncture, herbal medicine, or homeopathy, they usually do not ask for 'some form of CAM treatment'. Patients look for the best medicine for themselves. It is mostly of secondary interest to them if a treatment is delivered in a form that is complementary to conventional medicine or not. For this reason, I think the terminology should be adapted to the way it is commonly used by patients and delivered by physicians. Given the fact that CAM is used by $\geq 40 \%$ of patients in industrialised countries - mostly but not always in terms of an addition to conventional medicine why should we not use the term 'Integrative Medicine' to describe a form of treatment which consists of the 'best of' conventional medicine and traditional forms of healing [3]? This treatment approach can be connected with a constructive and meaningful therapeutic relationship which provides a sound basis for good communication between patients and health providers. In the future, this kind of new medicine could then open new perspectives for both patients and health providers.

The definition of the Consortium of Academic Health Centres for Integrative Medicine is aimed at this direction [4]: 'Integrative Medicine is the practice of medicine that reaffirms the importance of the relationship between practitioner and patient, focuses on the whole person, is informed by evidence, and makes use of all appropriate therapeutic approaches, healthcare professionals and disciplines to achieve optimal health and healing.' I believe that such an understanding of IM will be the future of medicine and will be acceptable for both patients and providers. However, two things have become clear: (1) At the moment, we still need the terms CAM and 'Conventional Medicine' to characterise the current situation of treatments and to create the basis for IM. (2) Further research in the field of CAM is required in order to create sufficient scientific evidence.

Also, we do need broad discussions on the terminology of CAM and IM. I therefore suggest that a special discussion symposium on terminology issues be organised. This symposium could also be linked to Work Package No. 1 on Terminology and Definitions of the new pan-European project 'CAMbrellla' - a research network for complementary and alternative medicine funded by the European Commission via the 7th Framework Programme on Health 2009. The main objective of this Work Package is to develop in a consensual process a new pan-European definition of CAM on the basis of existing terms and definitions of CAM analyses.

\section{References}

1 Walach H: «Integrative Medizin» - die Kolonialisierung des Anderen und die Notwendigkeit des ganz Anderen. Forsch Komplementmed 2010;17:4-6.

2 Dobos G: Integrative Medicine - Medicine of the future or 'Old Wine in New Skins'? Eur J Integr Med 2009;1:109-115.

3 Willich SN: Editorial. Eur J Integr Med 2009;1:163-164.

4 Consortium of Academic Health Centers for Integrative Medicine. www.imconsortium.org. 


\section{We Need a Conceptual Integration of Conventional and Complementary Medicine}

\section{Peter Heusser}

Center for Integrative Medicine

University of Witten/Herdecke

Germany

There are two main perspectives for the use of the term 'Integrative Medicine'. One refers more generally to the deliberate integration of all aspects of medicine into a coherent delivery of medical care, including the focus on the 'whole person', the use of 'all appropriate therapeutic approaches' and of the corresponding healthcare professionals and disciplines [1]. This more general notion of 'integrative' is not equivalent with, but includes, the second, more specific and more frequently used one: the integration of complementary and conventional methods in medicine [1]. In this latter sense, it has even become a habit to substitute the term 'Complementary' with 'Integrative' Medicine. But this is not appropriate. 'Integrative' literally designates the integration of parts into an encompassing unity; yet a part cannot replace the unity of which it is a part. 'Complementary' medicine complements 'conventional' to 'integrative' medicine.

However, 'Integrative Medicine' is mostly seen from the perspective of conventional medicine, as the set-up of the growing number of academic 'Centers for Integrative Medicine' shows. There, complementary methods are integrated into conventional institutions, research methodology, evidence based practice, and, most importantly, into the conventional framework of thinking. As a consequence, the intended 'unity' is conventional medicine; whereas the specific culture of 'unconventional' medicine runs the risk of getting lost in the 'conventional'. This is Harald Walach's concern when he likens the implementation of 'Integrative Medicine' to an act of 'colonization' of the 'other' or 'completely different' [2]. And he argues that only by keeping up its role as a counterpart can complementary medicine continue to exert its necessary function as an obstacle that provokes reflection, change and growth in conventional medicine.

I basically share Harald Walach's concerns, and I am also convinced that complementary medical disciplines should hold up their identities. However, with a slightly different aim. For me, the actual striving for 'Integrative Medicine' is already an expression of reflection, change and growth within conventional medicine, albeit within the conventional framework of thinking. The mechanistic interpretation of lifeprocesses, soul-life and spirit and the predominant focus on molecular interactions prevent an understanding of the immaterial holistically acting factors resorted to in various disciplines of complementary medicine. Therefore, 'Integrative Medicine' is at present not much more than a pragmatic jig- saw-puzzle of conceptually unrelated heterogeneous elements from conventional and complementary medicine.

What is needed is a step further: the conceptual integration of conventional and complementary medicine, the mutual understanding of their principles, a medical anthropology that encompasses both: the view on the molecular parts and the appreciation of their holistic organization, the reliance on physico-chemical processes and the acceptance of the immaterial nature of life, soul and spirit. But this will only be possible with a new way of thinking: when the concepts about the human being are neither derived from reductionist models, nor from non-provable holistic hypotheses, but from factually observed phenomena [3]. In this sense I pledge for a unified form of integrative medicine in both meanings mentioned above.

\section{References \\ 1 Consortium of Academic Health Centers for Integrative Medicine. www.imconsortium.org. \\ 2 Walach H: «Integrative Medizin» - die Kolonialisierung des Anderen und die Notwendigkeit des ganz Anderen. Forsch Komplementmed 2010;17:4-6. \\ 3 Heusser P, Mergelsberg J, Edelhäuser F: Towards a conceptual bridge between conventional medicine, integrative medicine and whole system approaches. Ab- stract Book, 5th International Congress on Complementary Medicine Research ICCMR 2010;O-029:13.}

\section{A Dispute about Nothing?}

\section{Bettina Reiter}

\section{Wien, Austria}

Terminological questions always are a tricky thing - as everybody knows. They come in a package with identity questions like: Who are we - the good ones - as opposed to them? Who is going to be included and who is going to be kicked out of the gang? Teminological issues are also narcissistic affairs: We do the right thing - we are the good ones! And they have to do with rivalry: And they, the others - do not! The terminology argument always goes for praising ones own apples and making the neighbours' ones look a little rotten, just a little...

I have been in favour of the term CAM for a long time, I thought it encompassed all the methods. It was quite pragmatic, but still gave the idea of having something other than conventional or academic medicines. I found the NCCAM definition of integrative medicine almost like a commercial for the product of a slim-lined and mainstreamed medicine that would fit into the hardboiled scheme of academic centres and still give the CAM softies a slogan to feel potent in stating that 'they combine the best of the two worlds'...

Then, at the ICCMR conference in Troms $\varnothing$ in May 2010, I heard Andrew Weil talk about his idea of 'Integrative 
Medicine'. And I admired the easiness of his super-pragmatic approach to the topic, which is not concerned with traditions, affiliations, ideas, or schools. Instead, his approach opens the room for the patient and their needs much more than the other definitions do. I like that - for the moment - and here it is:

Integrative Medicine is healing-oriented medicine that takes account of the whole person (body, mind, and spirit), including all aspects of lifestyle. It emphasizes the therapeutic relationship and makes use of all appropriate therapies, both conventional and alternative. The principles of integrative medicine are:

- a partnership between patient and practitioner in the healing process;

- appropriate use of conventional and alternative methods to facilitate the body's innate healing response;

- consideration of all factors that influence health, wellness, and disease, including mind, spirit, and community as well as body;

- a philosophy that neither rejects conventional medicine nor accepts alternative therapies uncritically;

- recognition that good medicine should be based in good science, be inquiry driven, and be open to new paradigms;

- use of natural, effective, less-invasive interventions whenever possible;

- use of the broader concepts of promotion of health and the prevention of illness as well as the treatment of disease;

- training of practitioners to be models of health and healing, committed to the process of self-exploration and selfdevelopment [1].

\section{Reference}

1 www.drweil.com/drw/u/ART02054/Andrew-Weil-Integrative-Medicine.html, as retrieved on June, 14, 2010

\section{Integrative Medicine: The Roof, the House and the Rooms}

\section{Andreas Michalsen}

\section{Immanuel-Krankenhaus}

Charité - University Medical Center

Berlin, Germany

The term 'Integrative Medicine' (IM) is a good choice as it clearly reflects the situation of patients and doctors of complementary medicine and naturopathy ('European Traditional Medicine', 'Naturheilkunde' = 'Natural Healing') at the current time: The majority of patients want to be treated with both and every doctor who applies these methods has also passed a conventional medical education.
However, there are some critical points to be aware of: Who defines the limits of IM? There are two extremes that both might not work in practice. One is that only evidencebased methods are included into IM ('cherry-picking'), the other would mean that IM is broad and unlimited, i.e. missing precision and endangering seriousness.

The widely cited definition of the Consortium of Academic Health Centers for Integrative Medicine says: 'IM is the practice of medicine that reaffirms the importance of the relationship between practitioner and patient, focuses on the whole person, is informed by evidence, and makes use of all appropriate therapeutic approaches, healthcare professionals and disciplines to achieve optimal health and healing' [1]. Probably or hopefully, every physician will be able to subscribe to this definition. It is a definition of good medicine and not of IM specifically. Notably, IM describes a procedural method or concept but not its content. IM is a suitable term to communicate the idea to politicians, stakeholders and academic decision makers. It also reassures that the purpose is not to compete with conventional medicine. However, we have to define what we aim to integrate. Otherwise IM would be a Trojan horse for the implementation of everything. Also, we should keep in mind that medicine has to be implemented in education. IM as a concept cannot be taught like other medical disciplines. We will never have a physician's exam in IM, as this would practically mean an exam about all medicine. Accordingly, a hospital or out-patient centre for IM still will have to define what it really integrates and the core of IM will be medical units where bilingual doctors will tailor patients' treatment pathways.

And what does IM integrate? The future of complementary and naturopathic medicine will depend on selecting and pushing the most efficacious treatment methods. I am concerned that 'Naturheilkunde' might become a victim of integrative globalisation. I strongly vote to prevent this from happening. 'Naturheilkunde' is the term most frequently used by the public and therapists in Central Europe. It has a logical basis that implies that the treatment methods are derived from natural sources and traces the concept of self-healing. Moreover, in advantage to other countries, in Germany 'Naturheilkunde' is an official board certification for medical doctors. We would be wise not to abolish our own traditional term while easily using Ayurveda, Kampo, and so on.

In fact, most of the efficacious methods of complementary medicine and Naturheilkunde are traditional methods. To my knowledge, only few, like e.g. vitamin supplements are nontraditional and, moreover, most non-traditional treatments are not evidence-based. Even the core of mind-body medicine is traditional. Thus, the most part of serious complementary and naturopathic medicine can be categorized as traditional medicine. With the perspective that worldwide traditional medicine experiences a renaissance we should also use this term. But what to do with 'Complementary Medicine'? 'Com- 
plementary Medicine' is widely used, however not known to most patients in Germany. Its definition is sound, but more of a defense and not positive. The problem with 'Complementary Medicine' is that all of its treatment methods with scientifically proven efficacy will be assimilated by conventional medicine. In the long run, for complementary medicine only the leftovers will remain.

In sum, I recommend to adopt the term 'Integrative Medicine' on an international and academic level, as the roof of the house. The house itself has several rooms, among them traditional medicine in every country, mind-body medicine, and, complementary medicine as a pool for other methods. We will have to define which treatment methods belong to which room and to accept that there are doors between the rooms and differences between countries.

If we agree to feature 'Integrative Medicine', we should do it strongly, as the term is also used by others in Medicine.

\section{Reference}

1 Consortium of Academic Health Centers for Integrative Medicine. www.imconsortium.org.

\section{Let's Be More Integrative without Being Exclusive}

\section{Claudia Witt}

Institute for Social Medicine, Epidemiology, and Health Economics Charité - University Medical Center

Berlin, Germany

The term 'Integrative Medicine' (IM) is becoming increasingly common and according to the Consortium of Academic Health Centers für Integrative Medicine refers to a medical approach which describes a practice of medicine that reaffirms the importance of the relationship between practitioner and patient, focuses on the whole person, is informed by evidence, and makes use of all appropriate therapeutic approaches, healthcare professionals and disciplines to achieve optimal health and healing [1].

'Alternative Medicine', 'Complementary Medicine' and the combination of the two, 'Complementary and Alternative Medicine' (CAM) are terms with a long history, whereas the development of the term 'Integrative Medicine' is much more recent. Another combined term which has also recently come to the fore is 'Complementary and Integrative Medicine' cited for example by the Mayo Clinic [2]. There is a lot of confusion about the terminology and the selection of a particular term is influenced by the individual perspective (e.g. patients, physicians, practitioners) and is often based on strategic decisions. However the terms have different meanings:
- 'Complementary and Alternative Medicine' includes those health care methods which are not commonly accepted as part of conventional medicine. If the treatment is instead of conventional medicine then the term 'Alternative Medicine' is used. However, if the treatment is in addition to conventional medicine the term 'Complementary Medicine' is adopted.

- 'Integrative Medicine' is the practice of an evidence-based combination of conventional and complementary health care which reflects the importance of the patient-practitioner relationship and a collaborative approach among practitioners for optimal patient care. If the treatments included are less evidence based, the appropriate term to reflect this would be Complementary and Integrative Medicine.

It appears that patients are less interested in the details of terminology: the most commonly used term in the population is still 'Alternative Medicine'. However, when asked about health care delivery, most patients prefer an approach with treatment options from both conventional and complementary medicine [3].

The providers' perspective is influenced by the providers' professional background. Practitioners are specialized mainly in complementary treatment methods (e.g. Chinese medicine, homeopathy), whereas physicians who offer complementary medicine usually combine it with conventional medicine.

I personally believe that the acceptance within mainstream medicine highly depends on the terminology used. It appears obvious that integration is only possible when the approach is based on evidence. 'Integrative Medicine' can provide the modern basis for the best possible comprehensive patient care due to the combination of the mutual strengths of both health care delivery systems [4]. However, one must be aware that this term, 'Integrative Medicine', is often misused, for example 'Complementary Medicine' may be offered with only restricted evidence and/or a limited focus on the whole person. This treatment is therefore not 'Integrative Medicine' as defined above and the term 'Complementary' would fit better. Overall, the term 'Complementary and Integrative Medicine' would, in my opinion, be the most comprehensive and would best reflect the reality in usual care.

\section{References}

1 Consortium of Academic Health Centers for Integrative Medicine in the US. www imconsortium org.

2 Mayo Clinic - General Internal Medicine in Minnesota. www mayoclinic org/ general-internal-medicine-rst/cimc html.

3 Dobos G: Integrative Medicine - Medicine of the future or 'Old Wine in New Skins'? Eur J Integr Med 2009;1:109-115.

4 Willich SN: Editorial. Eur J Integr Med 2009;1:163-164. 


\section{We Need a Pluralism of Therapies and Medicines}

\author{
Rainer Lüdtke \\ Karl and Veronica Carstens Foundation \\ Essen, Germany
}

'Integrative Medicine' (IM) is defined as the 'combination of mainstream with Complementary and Alternative Medicine (CAM), supposably leading to synergistic therapeutic effects' [1]. Although this sounds reasonable, the question remains, whether there is a need for IM as a new concept at all. Personally, I have some doubts, mainly for 4 reasons:

1. 'Integrative Medicine' is based on weak arguments. When German patients were asked whether they would prefer conventional medicine (COM), CAM, or a combination of both, 3 out of 5 patients preferred the last-mentioned alternative. This is sometimes taken as an argument, that 'Integrative Medicine' is a meaningful and popular concept [1]. But is this really true? Imagine you ask a person, independent of the context, if he or she likes concept $\mathrm{A}$, concept $\mathrm{B}$, or concept $\mathrm{AB}$ defined as the best of both! What would you expect? Any answer except $\mathrm{AB}$ would be a surprise, wouldn't it? In consequence, the above mentioned survey does not tell much about IM, it is simply a result of how the question was asked. (If anything, we should bother about those patients who opted for CAM or COM only.)

2. Integrative Medicine can be subsumed under Conventional Medicine. Today's mainstream medicine is based on the ideas of evidence-based medicine (EBM), defined as 'the conscientious use of current best evidence in making decisions about the care of individual patients or the delivery of health services.' This definition leaves it open, where the evidence based care is originated, be it from pharmacology, psychotherapy, CAM or elsewhere. Thus, integrative medicine emerges as identical to EBM ... and from this point of view the term IM is superfluous' [2]. Thus, there is no need for IM as a new concept. Though there is a need for a new way to practise EBM which has not yet shown to truly adopt evidence-based CAM therapies.

3. 'Complementary and Alternative Medicine' and 'Integrative Medicine' are interchangeably used. Although IM has a somewhat different concept than CAM (to fully integrate non-conventional therapies into usual care rather than to use them as a supplement), this perception has not (yet) been adopted by physicians in daily practice. Both are used as synonyms. Not even academic journals make a clear distinction. The journal 'Complementary Therapies in Medicine' for example refers in its title to CAM, but in its subtitle to IM: 'the Journal for Integrated Health'. And 'Alternative Therapies in Health and Medicine' defines its mission as 'to promote the art and science of integrative medicine ...'

4. Not even CAM is properly defined. Combining the best of two worlds (CAM and COM), as proposed by IM, assumes that there are indeed two worlds. But CAM is not an entity at all, it is an unstructured mixture of many health care ideas, ranging from simple diagnostic tools like hair analysis, over distinct therapies like leeches therapy to whole medical systems like homeopathy. There is no common idea, neither the 'holistic' nor the 'salutogenetic' approach nor the 'activation of self healing processes' fits it all.

CAM is not only improperly defined, it is also not perceived as an entity. When the Carstens Foundation recently asked $\geq 20$ German researches to name the 'most impressive CAM study in 2009', each responder came up with a completely different list of 5 studies, usually originated in the close field he or she worked in. No acupuncturist took note of Yoga, no homeopath of phytotherapeutic trials.

Conclusions: From my point of view IM might be useful as a political concept, aiming to give more focus on CAM therapies. But from a scientific point of view, I would suggest to reconsider Matthiessen's ideas, and to propose a pluralism of therapies and medicines, each of them concurring how patients can be helped best, but leaving space for each other to fit their individual needs for different approaches. This is why the Dialogue Forum on Pluralism in Medicine (www.dialog forum-pluralismusindermedizin.de/) is so helpful.

\section{References}

1 Dobos G: Integrative Medicine - medicine of the future or 'Old Wine in New Skins'? Eur J Integr Medicine 2009;1:109-115.

2 Ernst E: Integrative Medizin - Sammelbecken für Scharlatanerie jeder Art? Münch Med Wochenschr 2009;151:29-30. 